\title{
A bridge over troubled water? A qualitative study of primary care patients' experiences of a rehabilitation program
}

This article was published in the following Dove Press journal: Journal of Multidisciplinary Healthcare

Ingmarie Skoglund ${ }^{1,2}$

Eva-Lisa Petersson ${ }^{1,2}$

Dominique Hange ${ }^{1,2}$

'Närhälsan Research and Development Primary Health Care, Region Västra Götaland, Sweden; ${ }^{2}$ Department of Public Health and Community Medicine/Primary Health Care, Sahlgrenska Academy, University of Gothenburg, Gothenburg, Sweden

Correspondence: Dominique Hange Department of Public Health and Community Medicine/Primary Health Care Institute of Medicine, University of Gothenburg, PO Box 454, SE-405 30 Gothenburg, Sweden

Tel +463I 7736843

Fax +46 3I $778 \quad 1704$

Email dominique.hange@vgregion.se
Purpose: The aim of this study was to explore how patients on sick leave experienced and perceived the early collaboration work model (ECM) for rehabilitation.

Patients and methods: Data were collected via focus group discussions and individual interviews with 15 patients on sick leave, at nine primary health care centers. The systematic text condensation method described by Malterud was used for thematic analysis of meaning and content of data across cases.

Results: The participants perceived that sharing experiences with others in a similar situation was restorative. They described the importance of coordination in the program as well as the efforts of the rehabilitation coordinator, who helped with daily structure and support in the beginning as well as encouragement throughout the sick leave period. Some participants felt ashamed of being on sick leave and of being outside the community.

Conclusion: ECM with a rehabilitation coordinator who could share responsibility with the patient during the entire sick leave period was perceived to be of support during rehabilitation.

Keywords: coordination, health centers, mental health, sick leave, rehabilitation coordinator

\section{Introduction}

In Sweden, a welfare state, the rates of sickness absenteeism are high and just over the European average. ${ }^{1,2}$ Depression, anxiety, and stress-related mental disorders, usually referred to as common mental disorders, are some of the main causes of disability and affect $10 \%-15 \%$ of the adult Swedish population. ${ }^{3,4}$ Mental health disorders have become the main cause of longer periods of sick leave in Sweden and other economically developed countries. ${ }^{5}$

It is well known that the complexity of work ability, sick leave, and rehabilitation is large and that environmental factors often are very important for successful and lasting return to work (RTW). ${ }^{6}$ Successful RTW is promoted by continuity in contact with the professionals and cooperation between different actors such as physicians, physiotherapists, occupational therapists, nurses, psychologists, employers, the general insurance fund, and the employment office.

Swedish legislation regarding social insurance is based on a medical approach. However, the importance of the physical and psychosocial work environment in addition to the medical background is well documented concerning outcome in rehabilitation. The medical approach can lead to practical paradoxes with different actors whose tasks differ. ${ }^{6}$ A literature review has shown that successful interventions improved psychological health and levels of sickness absence by training and organizational 
approaches to increase participation in decision making and problem solving, increasing support and feedback, and improving communication. ${ }^{?}$

It is difficult to develop evidence-based programs in work-oriented rehabilitation as the conditions are individual and complex. However, through internationally tested programs, the following aspects are known to be important and generally implicated in RTW: early and multi-professional assessment focusing on aspects such as health, work and life situations, individual action programs that take into account the assessment of various aspects, action programs in collaboration between the patient and the employer/ workplace as well as the health care system action programs with goals related to RTW, and that the patient on sick leave has regular contact with and assistance from a coordinator. ${ }^{6}$ During the last 10 years there has been an increasing interest in coordinating rehabilitation. In a Cochrane survey covering musculoskeletal disorders, mental health problems, and cancer, the authors concluded that the effectiveness of workplace interventions on work disability showed varying results. Workplace interventions reduced time to RTW and improved pain and functional status in musculoskeletal disorders. No evidence was found for any considerable effect of workplace interventions on time to RTW in workers with mental health problems or cancer. ${ }^{8}$ In Sweden, some work concerning rehabilitation coordinators has been undertaken by the Swedish Association of Local Authorities and Regions. The coordinator has been described as a spider in the web concerning rehabilitation, ${ }^{9}$ where the role of that person is to coordinate sick leave and rehabilitation while giving support to the patient and preparing possibilities for RTW. ${ }^{10}$ Scientific literature concerning rehabilitation, primary health care, and patients' perspective and coordination is scarce according to a PubMed search. ${ }^{11}$

The Region Västra Götaland and the Swedish Social Insurance Agency have since January 2013 collaborated to achieve a more effective rehabilitation process for those patients on sick leave who are in need of extended support for their rehabilitation both at public and at privately managed primary health care centers, the "Early Collaboration Work Model" (ECM). ${ }^{12}$ This is based on a click tool with templates for different steps in the rehabilitation process. The aims have been to ensure that the patient gets the right effort in due time, to reduce the number of days on sick leave, and to investigate how patients on sick leave perceive the benefits and effectiveness of the rehabilitation. The process starts when a person seeks care as is triaged to be in need for support. During the following steps the health care centers locally elaborate and document their specific work with the patients in a structured way. The structured questions are about: Which action is already taken? Who is responsible for that action? What is included in the rehabilitation plan? Are contacts already taken with the employer, the general insurance fund, or the employment office? What problems might occur? Each step describes the purpose of the routine, who is responsible, and who executes the routine. Any diagnoses or symptoms that could need extended support for rehabilitation may be relevant. The methods and means used in ECM rehabilitation were adapted to the specific needs. ECM has also included simplified procedures for the physician to issue certificates of sick leave.

\section{Aim}

The aim of this study was to explore how patients on sick leave experienced and perceived the ECM for rehabilitation.

\section{Patients and methods}

In this study, we used Malterud's systematic text condensation (STC).${ }^{13}$ STC is a thematic analysis of meaning and content of data across cases. All patients who took part in the project $\mathrm{ECM}^{14}$ were invited to participate in the present study. Totally 15 patients were included (11 females and four males), mean age 45.0 years, living in medium-sized cities and villages, attending nine primary health care centers in Region Västra Götaland (Table 1). The main diagnoses (11/15) on the sick leave certificate were mental health problems (symptoms of exhaustion and depression), perhaps reflecting the Swedish situation concerning sick leave. ${ }^{5}$ The other diagnoses were osteoarthritis, herniated disc, back injury, and condition after cancer treatment. The participants' own description contained physical symptoms such as dizziness as well as psychological symptoms such as anxiety and cognitive symptoms such as lack of concentration, which also have been seen in other studies in patients with stress-related exhaustion ${ }^{15}$ as well as depression and anxiety. ${ }^{16}$

One focus group was conducted with four participants, one with three (one participant dropped out immediately before the set appointment), and one group with two participants (because the primary health care centers were located far apart from each other). For those where it was not possible to fit in an appointment for a focus group, as well as for the participants who preferred it, individual interviews were offered. Six patients were individually interviewed.

The participants in our study were invited by telephonic conversations. All of them received a letter with written information about the study in advance, as well as verbal information right before the focus groups/interviews. 
Table I Information concerning gender, age, interview type, and working status for the 15 patients

\begin{tabular}{llllll}
\hline Participants & Gender & Age & Interview type & Working status & Sick leave \\
\hline I & Female & $6 \mathrm{I}$ & $\mathrm{F}$ & Employed & Yes \\
2 & Female & 58 & $\mathrm{~F}$ & Employed & Yes \\
3 & Female & 39 & $\mathrm{~F}$ & Employed & Partially \\
4 & Male & 58 & $\mathrm{~F}$ & Unemployed & Yes \\
5 & Male & 42 & $\mathrm{~F}$ & Employed & No \\
6 & Female & 29 & $\mathrm{~F}$ & Student & Studies \\
7 & Male & 32 & $\mathrm{~F}$ & Employed & No \\
8 & Female & 47 & $\mathrm{~F}$ & Employed & No \\
9 & Female & 44 & $\mathrm{~F}$ & Unemployed & Yes \\
10 & Female & 52 & $\mathrm{I}$ & Employed & Yes \\
II & Male & $5 \mathrm{I}$ & $\mathrm{I}$ & Employed & Employed \\
12 & Female & 39 & $\mathrm{I}$ & Employed & No \\
13 & Female & 56 & $\mathrm{I}$ & Employed & No \\
14 & Female & 49 & $\mathrm{I}$ &
\end{tabular}

Abbreviations: $F$, focus group; I, individual interview.

Data were collected through individual interviews and focus groups in the primary health care centers from autumn 2016 through winter 2017. A focus group involved a special type of discussion in terms of purpose, size, composition, and procedures; the method is suitable for use when different perspectives are needed on an issue that is not as well developed. ${ }^{17,18}$ The discussion generates a range of views without presenting a consensus, and disagreements within the group are welcome, since that can promote the discussion and clarify different responders' points of view. A topic guide for both focus groups and interviews was constructed based on the aim of the study. A semi-structured interview guide was developed for the individual interviews. ${ }^{19}$

All our focus groups had a moderator and an assessor. The moderator (alternating between Dominique Hange and Ingmarie Skoglund) initiated the discussion by describing the focus group procedure as well as the topic for the discussion. The group was instructed to discuss the topic without any involvement from the moderator or the assessor. The moderator only helped the group to be focused on the topic. The assessor's role was to help the moderator make clarifications when ambiguities occurred or to deepen the discussion.

The topics focused on the patients' own thoughts and experiences of participating in ECM, and questions such as "how would you describe your rehabilitation?", "how did you perceive ECM as a model?", and "what did you experience after the end of ECM?" served to improve data collection. The Supplementary material provides a list of the questions. The meetings lasted no longer than 1.5 hours. All sessions were audiotaped and transcribed verbatim.
The Regional Ethical Review Board in Gothenburg, Sweden approved this study (Dnr 429-16; June 21, 2016). All participants gave their written informed consent to participate in the study, in accordance with the provisions of the Declaration of Helsinki.

\section{Analysis process}

In the analysis, Malterud's $\mathrm{STC}^{13}$ was used. This method was inspired by Aanstoos and Giorgi's phenomenological analysis,${ }^{20}$ and included the following steps.

- Initially, all three authors read the material several times to obtain an overall impression of the data.

- Second, the authors identified units of meaning, representing different aspects of the research question, and performed coding and sub-coding for these.

- Third, the contents of each of the coded groups were condensed and summarized.

- Finally, descriptions were developed, reflecting the participants' most important experiences of ECM.

Malterud's STC was chosen because it offers a process of feasibility, intersubjectivity, and reflexivity during the analysis of qualitative data. The methodological rigor makes the steps easy to follow.

All of the researchers had experience of working in primary health care, and the level of prior understanding of the context was high. However, none of the researchers had worked with ECM at their practice. To achieve trustworthiness, the researchers engaged in an ongoing process of discussion and reflection throughout the process of analysis. 


\section{Results}

The participants perceived that sharing experiences with others in a similar situation was restorative. They described the importance of coordination in the program as well as the efforts of the rehabilitation coordinator, who helped with daily structure and support in the beginning as well as encouragement throughout the sick leave period. Some participants felt ashamed of being on sick leave and of being outside the community.

These findings have been elaborated below with selected quotations.

\section{Shared experiences and a toolbox for life}

Participating in a group gave many participants a wider view, both concerning their own situation and concerning actions and tools that could be used to move on. Before the group started, several participants expressed worry because they did not know what they could expect. There were also participants who clearly expressed that they did not want to participate in group activities but instead preferred individual rehabilitation.

I was very hesitant as I was offered to participate in the stress course and thought I'll sit there and talk to a lot of strangers. Imagine if someone is from my neighborhood (?). I have no desire to share my experiences, but then when the course went on, yes, I was doing well and it was not that dangerous. Then we were still three out of six from the same district. But it gave so much and became so good you should not hesitate.

It's not about the group itself, because although I was sitting there among a lot of people, I did not notice them, but I was there for my own sake and focused on what they said, but no, it made me depressed. But then there could be another group activity that might be great but I have not found it yet.

For those who dared to take the step to participate in a group, the experience became positive. Not primarily focusing on the "other" enabled the participants to speak out more personally and in a freer mood. Several participants realized that they became friends who could help each other and exchange experiences regarding "when we will climb that mountain." Participants clearly appreciated being able to get more suggestions regarding actions from a group compared to conversations with just one individual as in the case of a traditional consultation with professionals. Group conversations were perceived as positive, partly because others could have been involved in similar situations and were able to share their experiences and partly because one could get the group's opinion about what one could do or think in a special situation.

But what was absolutely amazing in this group was that we got four aspects of how we might ... could handle the problem. When you try one of these four options and it works better than your own ... in this way you can consider yourself from the outside.

An example of group activity was "the life wheel" course, where the participants learned and realized how stress may influence their lives. The importance of an everyday structure was mentioned as well as other measures which could help them cope with their life situations.

Some insights that were brought forward were the importance of patience and to understand that things change and change takes time.

Yes, I want to be the same person, but I do not want to do the same things. And I also think that these courses have been very good at clarifying because there are many who have fatigue, depression, or symptoms who say you will never be yourself again. Stop it, that is very provoking! I do not want to be a new person but I want to learn to cope differently. That's a big difference that the courses have helped me to formulate.

Other group activities were meditation and mindfulness; both were thought to be of great importance although not performed daily. For several participants, medical yoga was considered to be remarkable as it enabled them to cope even if they were not cured. Many participants felt that physical training was very important and they tried to implement it regularly, although there were not as many occasions as originally thought. It was expressed that it was important to find an exercise that suited participants and that it was not only good for the physical part. "So the training, that's A and O. But again it's not just for the body."

\section{Rehabilitation coordination as a lighthouse in the storm}

Many participants had good experience of the health care personnel taking over the responsibility or sharing the responsibility of care with them. They believed health care personnel understood what was wrong with the participants long before they understood that themselves.

\footnotetext{
More people became involved and things like that. It felt safe for me because I relied on the staff at the health centers. It made me feel very secure that other people could think for me, telling me what to do in a positive way.
} 
All participants indicated that the rehabilitation coordinator was the most important health professional in the rehabilitation process. The participants defined her as a pilot, a "lifeline," or a thick rope to hold onto, and several expressed that she was an outstanding person who was easy to talk to and easy to reach. Through her presence, kindness, knowledge, and accessibility, she gave their lives increased safety in an anxious and often chaotic situation. At the beginning of the rehabilitation, the conversation could cover themes such as how to manage the structure for everyday life because many of the participants could not grasp at all what was happening around them.

There were like wild horses in my brain but with the tools I learned in the course, I could calm the brain down in a way and prevent the autopilot from going back to the already known paths.

The rehabilitation coordinator had knowledge about how to handle sleep, everyday stress, and panic attacks, as well as setting boundaries and prioritizing them. The participants were too weary to read a book or watch TV and remembered nothing of the content afterwards, which naturally had an influence on their conversation. It was too difficult to work in a structured manner when they felt that they had no structure inside themselves and could not handle any written information or instruction. The understanding of the importance of a structure became clearer during the course of the rehabilitation and the participants felt more able to abide by it.

In the beginning of the sick leave, it was most important to focus on an everyday structure. I could not manage thinking about what would be the best for me when I go back to work. At the same time the process to go back must begin somewhere ... So yes, she (the rehabilitation coordinator) gave me a structure, because I could not manage to make it myself.

What I can see now is that the structure has helped me back in a good way, where one could meet the difficulties in time. ... I was not able to act like this before, because I was ... you vacillate so very much. You do everything you can to keep your head above the surface of the water and you cannot look forward.

The participants described the meetings with the rehabilitation coordinator as very useful during the rehabilitation process. They were impressed by the rehabilitation coordinator's way of working and perceived her as an actively listening person who had professional experience in the field. Her questions led them into new thoughts and priorities, to find out what was important and to be able to think in new and different ways.

But it has strengthened me to get out of this and to understand myself, to find myself, an inner journey you can say, it has been incredible ... I know why I got sick ... Although I tried to highlight these things for the last 2 years. I understood it all now when I spoke to the rehabilitation coordinator.

They developed a language to describe their feelings and mood and found new strategies to feel better. The rehabilitation coordinator also could tell them not to do things or to choose to do "positive" things.

I learned that as soon as I felt tired, the special fatigue that was not good, I went to bed, or went and rested, or did something that was good for me. Listened to music that was relaxing, nice music not strange and I could just sit outside in the sun if I felt like that.

Through conversations with the rehabilitation coordinator, they also could get suggestions about how to tell their families and friends, how to be supported as well as to be left alone without demands when needed.

Yes, I've been honest and said it's not possible. I do not feel good. I'm not coming. But this you should do, no, I will not come because of my illness. So I've been very clear about it and said, I will not contact you until I'm feel(ing) better.

This is how it is, no use of fighting against it and trying, as I did before, it's not possible. It's pretty nice, partly sad ... So I try to accept ... and make others understand that this is how it is.

The rehabilitation coordinator also contacted other health professionals, such as physicians when there was a need for medication. Contact via the rehabilitation coordinator made it possible for participants to access the needed resources more quickly, directly through the health care center.

The cooperation between the rehabilitation coordinator and the team was highly appreciated.

I did not want to take medication at the beginning ... so it took some time before I started with them. So I started with the psychologist and then came the nurse ... so I started with her when I first started with the medication because she would keep a close eye on me with the medication and so I thought that was very safe.

The rehabilitation coordinators' contacts and explanations about the patient and the illness, in the dialogues with both 
employers and Swedish Social Insurance Agency, were perceived by all of the participants as valuable, as they eliminated the risk of misunderstanding and, for example, reduced the necessity that the patients themselves should inform about their situation at workplace meetings and other forums.

Then I think the employer pays a bit more attention, too, when a rehabilitation coordinator is calling... Oh, here we have to hurry up. I noticed that I got help a lot faster with regard to getting to the occupational health center when there was someone else (rehabilitation coordinator) who called.

I had one from Swedish Social Insurance Agency who had no knowledge at all about exhaustion, and because of that, it was very good that my rehabilitation coordinator and doctor could explain ... plus that my rehabilitation coordinator could say what the rules were, yes she even knew about the Swedish Social Insurance Agency rules. It became safe.

Other participants described good support from their employer during the sick leave and RTW.

The first 3 weeks after return to work, I did not do that much. I was mostly at work, yes, just getting used to me being me and just being without responsibility. It felt nice and my employer was very clear about me taking it at my own pace and not feeling any pressure from their side.

Taking responsibility over their own situation was described as very important, but the participants did not always have the strength to do so. They felt tired and vulnerable. At the same time, some of them felt worried about what would happen if they would allow someone else to take over the responsibility.

I'm probably both a violin string and at the same time I feel

I cannot be that. So now I have to let it go.

\section{Regulations govern shame and guilt}

Many of the participants thought it was obvious that they did not want to be on sick leave, and often experienced discomfort over it; it did not feel loyal to be home from work and lose participation in the community. They were outside and felt ashamed of not hurrying to get better, as well as needing help from their employers and physicians to come back.

It's a difficult piece to accept. That in fact, some days I cannot even take care of everything that I always used to be able to do before. I think it is hard.

Feelings of guilt and shame, because of their sick leave, could emerge in situations where they were in the risk of meeting people they knew. The fear of beginning to cry or that the situation would be embarrassing could cause the participant to avoid shopping or celebrating birthdays. They felt that it was difficult that people in their surroundings had to know how to deal with their illnesses, unlike cancer or a broken leg.

Feelings of fear could emerge in contact with their employers, when the participants perceived that the workplace had a great deal to do with their illness. The fear of losing their employment, however, could lead them to go back to work early.

Still, you have to go back to work eventually and its a huge worry when you're sick and if you're on sick leave, its even worse, especially when its perhaps the workplace that made you sick. Because then your work is in some way so very much connected to the way you feel. Just thinking about the job makes you get these feelings.

Work training was also perceived as leading to a "special kind of work" (stooge around) "in a dark shelter somewhere where I can sit and make something, put screws in a jar or something like that."

Some participants described the meetings with administrators at the Swedish Social Insurance Agency as demanding and stressful. The perceived lack of understanding of their medical situation as well as the standard template (staircase model) of sick leave. The model is very strict and contain four different levels of sick leave; $25 \%, 50 \%, 75 \%$ respective $100 \%$. The impossibility of working for example $40 \%$ as well as the feeling of distrust from the environment could lead to feelings of anxiety and loss of energy. When there was a disagreement between the physician prescribing sick leave and the Swedish Social Insurance Agency's view or other difficulties in the health care system, such as long waiting times for investigations or treatments, the participants felt frustrated.

It does not seem like they have any work experience, the administrators at the Swedish Social Insurance Agency, they are more like small machines, doing something that someone else has decided.

You can look at it as I do, I usually say that I have become a piece of raw material for the Social Insurance Agency. Imagine that he who is earning money there is actually living on yours.

\section{Discussion}

The participants in this study perceived that sharing experiences with others in a similar situation was restorative. They described the importance of coordination in the program as well as the efforts of the rehabilitation coordinator, who helped with daily structure and support in the beginning as well as encouragement throughout the sick leave period. 
They mentioned the importance of her knowledge about the rehabilitation process and her willingness to share it with them in the right time and in a proper way. Some of the participants perceived her as their lifeline in a very chaotic situation as well as a direct pathway into the health care center.

The participants also mentioned feelings of shame and guilt regarding the entire situation due to being on sick leave, and fear of losing work emerged as a concern.

\section{Strengths and weaknesses of the study}

A strength of this study was that the participants were acceptably diversified in age and gender. The predominance of females is well consistent with the fact that more females than males are on sick leave for mental health problems. Their residence varied from living in medium-sized cities to living in the country side. They had all taken part in the ECM and were able to provide rich experiences of ECM. The participants presented their experiences openly and honestly. The researchers had different occupations (general practitioners and occupational therapist), creating broad analytic space, which increased the validity of the results. The number of participants was considered sufficient given the aim of the study as well as using STC as the method.

The analysis was performed in cooperation with all authors and sought to adhere strictly to the guidelines of the STC method.

A limitation of the study was the relative homogeneity of the participating patients' diagnoses. The majority suffered from depression or stress-related exhaustion, and participants with other diagnoses might have had other experiences. On the other hand, this could be interpreted as a strength, because the diagnosis reflects the primary cause of sick leave today.

Participants were all native Swedes, which might have influenced both their understanding of the health care system as well as the Swedish Social Insurance Agency. Participants from different countries could have given the study another cultural dimension. We recruited the participants at their primary health care centers during the limited time period for our study. Since ECM had been ongoing for $>2$ years at different primary health care centers, there could be differences regarding the rehabilitation activities that were available. One of the three focus groups consisted only of two participants, which normally would be too less to enable an extensive discussion, but since these two participants were very eloquent and could clearly describe their experiences, the discussion became illuminating.

The rehabilitation coordinator could have a large influence of the ECM due to her obviously charismatic personality; therefore, a future study would need to discern whether the ECM was helpful because of its contents, or because of the singular positive influence of the rehabilitation coordinator.

Our findings might be transferable to other primary health care centers in Sweden, since many of the centers work under the same conditions. We formed focus groups and conducted interviews with patients at nine different centers. All primary health care centers but one in this study were in the public sector, and patients from private primary health care centers might have responded differently. Participants in the individual interviews might have had more difficulty in remembering their experiences compared to the participants in a focus group, who could discuss the themes together. The time between their participation in ECM and our study was not $>1$ year for any of them, but some effect of recall bias on the results cannot entirely be excluded.

All authors have several years of work experience in primary care settings and have preconceptions about how it is to work at a primary care center, but none of us have worked with ECM. This might have partly influenced the analysis of the material.

\section{Findings in relation to other studies}

Our study evaluated the participants' experience of their rehabilitation in primary care. Results showed that many of the patients experienced a longing for a person or a team who could share the responsibility with them from the first meeting and throughout the entire period of sick leave. They wanted to feel their empowerment in the process, and yet have the opportunity to ask for help when needed. The participants' perceptions of the assignments performed by the rehabilitation coordinator are well in line with the definition of the rehabilitation coordinator function as described by the Ministry of Social Affairs. ${ }^{21}$ Co-financed teams with personnel from primary care, social insurance, and social services have earlier been found to have a positive effect on organization but not on patient health outcome, when compared to conventional care. ${ }^{22}$

Having a special person, a care manager, who is responsible for providing support to and maintaining continuous contact with patients with depression has previously been shown to be of great importance for coming back to work earlier after sick leave. ${ }^{23,24}$

The rehabilitation coordinator acted as a mediator in different meetings, for example between the participants and their employers. The participants appreciated the possibility of clear communication to eliminate misunderstandings in contact with their workplace. They often had the fear of los- 
ing work because of being on sick leave. There can also be a fear of getting back to work too soon, if one perceived that it was the work that caused the illness, but on the contrary, it may be very helpful to work if the illness originated from something external to work. The fear of losing work is a fear related to the individual's place in society and the ability to continue the way of life that she is used to. ${ }^{25}$ Fear can also cause different kinds of symptoms as well as illnesses.

Few studies have examined how patients on sick leave perceive the benefits and effectiveness of rehabilitation. Luker et al pointed out the importance of patient-centered care as well as more effective communication and information, ${ }^{26}$ and another study focused on the interaction between the physiotherapist and the patient. ${ }^{27}$ To our knowledge, however, there are no previous studies concerning rehabilitation coordination.

Perceptions of utility and efficiency cannot be quantified through measurements. In our society, the concepts of utility and efficiency have a utilitarian character. This means that these notions are not only deliberately but also unconsciously characterized by assumptions about how to maximize the benefits to the greatest possible extent. Concerning benefits, the concept of "prompt and pragmatic benefit" has been shown to be meaningful as a way of understanding how general practitioners think when it comes to prescribing drugs. It has also been meaningful in other contexts, both within and outside of health care. The concept implies that conditions close at hand, in time and space, are easier to implement and use than if they are more complex. It is therefore possible that the concept could be understandable for people who participate in rehabilitation in different ways. ${ }^{28}$

Although the participants described their rehabilitation activities almost solely in positive terms, with some improvement emerging above all, the time table for the rehabilitation could sometimes be perceived as too short or requiring that the patients themselves had to take a greater step forwards, than they felt able to do. They mentioned the rules of the Swedish Social Insurance Agency as creating difficulties at times, and felt obliged to participate in work training during the sick leave, but found it too difficult because of their symptoms.

Some of the participants felt forced by the Swedish Social Insurance Agency to return to their work "too early." Other studies have pointed out the importance of the prognosis in the patients' self-predicted timing of RTW. ${ }^{29}$ The importance of the environment's support for persons on sick leave, to strengthen their confidence in their own ability and their role in coming back to work, has been shown previously. ${ }^{30,31}$
Some participants described feelings of shame and guilt because of their symptoms (eg, lack of energy and tearfulness), and their situations (being on sick leave). There is a well-known association between shame and symptoms of depression, ${ }^{32}$ and the patients' feeling of shame might even prolong sickness absence. ${ }^{33}$ Employees on long-term sick leave felt the fear of losing their job within the next 2 years. ${ }^{34}$

It might be difficult for one model or program to provide all the measures needed to get all patients on sick leave back to their work, but ECM with the rehabilitation coordinator as a central person with knowledge about the illnesses (the patients "side"), the work, and the employer, as well as the Swedish Social Insurance Agency system and other possibilities appears to have a good potentiality to help patients to move forward in their rehabilitation and hopefully back to work again. ECM seemed to help the participants to find tools and other ways of thinking and attacking problems, especially in relation to mental health. Some participants mentioned the strength to gain experience through Internet via blogs. The coordination function can be handled by others, for example a care manager, ${ }^{23}$ and some patients might feel too fatigued to come to the Primary Health Care Centers at the beginning of the sick leave and other forms of contacts can be needed such as apps.

\section{Conclusion}

ECM with a rehabilitation coordinator who could share responsibility with the patient during the entire sick leave period was perceived to be of support during rehabilitation.

\section{Acknowledgments}

The study was financed by grants from Region Västra Götaland as well as Närhälsan Research and Development Primary Health Care, Södra Älvsborg of Sweden. The study sponsors had no role in the collection, analysis, and interpretation of data, or the writing of this report, or the decision to submit the article for publication. All authors were independent from the funders. The authors are grateful to Eva Hällås and Märit Löfgren for support and cooperation.

\section{Disclosure}

The authors report no conflicts of interest in this work.

\section{References}

1. Statistics Sweden (Statistiska Centralbyrån SCB). Mans medellivslangd for forsta gangen over 80 ar [Men's average life expectancy for the first time over 80 years]; 2014:16. Available from: https:/www.scb.se/sv_/ Hitta-statistik/Artiklar/Mans-medellivslangd-for-forsta-gangen-over80-ar/\#. Accessed January 04, 2018. Swedish. 
2. Hagglund P, Johansson P. Sjukskrivningarnas anatomi - en ESO-rapport om drivkrafternai sjukforsakringssystemet [Anatomy of sick leave - an ESO report on the driving forces]. In: Finansdepartementet, editor. Vol 2;2016. Swedish

3. National Board of Health and Welfare (Socialstyrelsen). Behandling av Depressionssjukdomar: En Systematisk Litteraturoversikt [Treatment of Depression Diseases: A Systematic Literature Review]. Stockholm, Sweden: SBU; 2004. Swedish.

4. National Board of Health and Welfare (Socialstyrelsen). Behandling av Angestsyndrom: En Systematisk Litteraturooversikt [Treatment of Anxiety Disorder: A Systematic Literature Review]. Stockholm, Sweden: SBU; 2005. Swedish.

5. Henderson M, Harvey SB, Overland S, Mykletun A, Hotopf M. Work and common psychiatric disorders. J R Soc Med. 2011;104(5):198-207.

6. Ekberg K, Eklund M, Hensing G. Atergång $i$ arbete. Processer, bedomningar, atgarder [Return to Work. Processes, Assessments, Measures]. Sweden: Studentlitteratur AB; 2015. Swedish.

7. Michie S, Williams S. Reducing work related psychological ill health and sickness absence: a systematic literature review. Occup Environ Med. 2003;60(1):3-9.

8. van Vilsteren M, van Oostrom SH, de Vet HC, Franche RL, Boot CR, Anema JR. Workplace interventions to prevent work disability in workers on sick leave. Cochrane Database Syst Rev. 2015;10:CD006955.

9. Hansen Falkdal A, Hornqvist Bylund S, Edlund C, Janlert U, Bernspång B. Nationell utvardering av koordinatorsfunktionen inom sjukskrivnings- och rehabiliteringsomradet. Rekoord-projektet [National evaluation of the coordinator's function in the field of sick leave and rehabilitation]. County Council of Vasterbotten in cooperation with Umeå University and MID Sweden University. Umeå, Sweden; 2013. Swedish.

10. Hansen Falkdal A, Ekvall A-B, Eklund U; Sveriges Kommuner och Landsting. Metodbok för koordinering av sjukskrivning och rehabilitering för halso- och sjukvarden [Book of Methodology for Coordinating Sick Leave and Rehabilitation for Health Care]. Stockholm, Sweden: Swedish Association of Local Authorities and Regions (Sveriges Kommuner och Landsting); 2017. Swedish.

11. Kuoppala J, Lamminpaa A. Rehabilitation and work ability: a systematic literature review. J Rehabil Med. 2008;40(10):796-804.

12. Bjork L, Paulsson S. Slutrapport "Tidig samverkan i Vastra Gotaland" Inforande av arbetsmodellen Guide for tidig samverkan och fordjupade forsok på vardcentraler [Early collaboration in Vastra Gotaland. Introduction of the work model and in-depth attempts at healthcare centers]. 2017. Region Västra Götaland, Sweden. Swedish.

13. Malterud K. Shared understanding of the qualitative research process. Guidelines for the medical researcher. Fam Pract. 1993;10(2):201-206.

14. Bjork L, Paulsson S. Tidig samverkan i Vastra Gotaland - inorande av arbetsmodellen Guide för tidig samverkan och fordjupade forok pa vardcentraler [Early collaboration in Vastra Gotaland. Introduction of the work model and in-depth attempts at healthcare center]. Region Västra Götaland, Gothenburg, Sweden; 2017. Swedish.

15. Glise K, Ahlborg G Jr, Jonsdottir IH. Prevalence and course of somatic symptoms in patients with stress-related exhaustion: does sex or age matter. BMC Psychiatry. 2014;14:118.

16. Bertilsson M, Petersson E-L, Ostlund G, Waern M, Hensing G. Capacity to work while depressed and anxious - a phenomenological study. Disabil Rehabil. 2013;35(20):1705-1711.
17. Morgan D. Focus Groups as Qualitative Research. 2nd ed. Thousand Oaks, CA, USA: Sage Publications; 1997.

18. Krueger RA, Casey MA. Focus Groups: A Practical Guide for Applied Research. 4th ed. Thousand Oaks, CA, USA: Sage Publications; 2009.

19. Kvale S. Interviews: An Introduction to Qualitative Research Interview ing. Thousand Oaks, CA, USA: Sage Publications; 1996.

20. Aanstoos C, Giorgi A. Phenomenology and Psychological Research. Pittsburgh, PA: Duquesne University Press; 1985.

21. The Ministry of Health and Social Affairs (Socialdepartementet). Rehabilitering skoordinatorfunktion [The Function of the Rehabilitation Coordinator]. Stockholm, Sweden: The Ministry of Health and Social Affairs; 2017. Swedish.

22. Hultberg EL, Lonnroth K, Allebeck P. Interdisciplinary collaboration between primary care, social insurance and social services in the rehabilitation of people with musculoskeletal disorder: effects on self-rated health and physical performance. J Interprof Care. 2005;19(2):115-124.

23. Bjorkelund C, Svenningsson I, Hange D, et al. Clinical effectiveness of care managers in collaborative care for patients with depression in Swedish primary health care: a pragmatic cluster randomized controlled trial. BMC Fam Pract. 2018;19(1):28.

24. Swedish Council on Health Technology Assessment. Implementation of psychiatric guidelines and evidence-based knowledge in the primary care sector. SBU report no 211. Swedish Council on Health Technology Assessment; Stockholm, Sweden. 2012.

25. Bauman Z. Liquid Fear. Cambridge, UK: Polity Press; 2006.

26. Luker J, Lynch E, Bernhardsson S, Bennett L, Bernhardt J. Stroke survivors' experiences of physical rehabilitation: a systematic review of qualitative studies. Arch Phys Med Rehabil. 2015;96(9):1698-1708, e1610.

27. Del Bano-Aledo ME, Medina-Mirapeix F, Escolar-Reina P, MontillaHerrador J, Collins SM. Relevant patient perceptions and experiences for evaluating quality of interaction with physiotherapists during outpatient rehabilitation: a qualitative study. Physiotherapy. 2014;100(1):73-79.

28. Skoglund I. Prescribing Drugs in Primary Health Care - Thoughts, Information Strategy and Outcome. Sweden: Institute of Medicine, Sahlgrenska Academy, University of Gothenburg; 2012. Available from: http://hdl.handle.net/2077/29712. Accessed April 04, 2018.

29. Lund T, Labriola M, Christensen KB, Bultmann U, Villadsen E. Return to work among sickness-absent Danish employees: prospective results from the Danish Work Environment Cohort Study/National Register on Social Transfer Payments. Int J Rehabil Res. 2006;29(3):229-235.

30. Briand C, Durand MJ, St-Arnaud L, Corbiere M. Work and mental health: learning from return-to-work rehabilitation programs designed for workers with musculoskeletal disorders. Int J Law Psychiatry. 2007;30(4-5):444-457.

31. van Oostrom SH, Anema JR, Terluin B, Venema A, de Vet HC, van Mechelen W. Development of a workplace intervention for sick-listed employees with stress-related mental disorders: intervention mapping as a useful tool. BMC Health Serv Res. 2007;7:127.

32. Kim S, Thibodeau R, Jorgensen RS. Shame, guilt, and depressive symptoms: a meta-analytic review. Psychol Bull. 2011;137(1):68-96.

33. Knapstad M, Overland S, Henderson M, Holmgren K, Hensing G. Shame among long-term sickness absentees: correlates and impact on subsequent sickness absence. Scand J Public Health. 2014;42(1):96-103.

34. Kullander M, Eklund O. Sick Leave and Fear of Losing One's Job. London: Oxford Research; 2010. 


\title{
Supplementary materials
}

\author{
Interview guide for the focus groups \\ I. How do you perceive the rehabilitation (ECM) you have taken part in? \\ 2. Have your thoughts of rehabilitation changed after ECM, and if so, how? \\ 3. What kind of information did you receive about ECM before it began? \\ 4. How did you perceive your own role in your rehabilitation? \\ 5 . In which way could your own experiences be useful in ECM? \\ 6. What can you tell us about possible benefits of ECM for you? \\ Interview guide for the individual interviews \\ I. How did you think about rehabilitation before you took part in ECM? \\ 2. How do you perceive the rehabilitation (ECM) you have taken part in? \\ 3. Have your thoughts of rehabilitation changed after ECM, and if so, how? \\ 4. What kind of information did you receive about ECM before it began? \\ 5. How did you perceive your role in your own rehabilitation? Has it changed after ECM? In which way? \\ 6. In which way could your own experiences be useful in ECM? \\ 7. What can you tell us about the possible benefits of ECM for you? \\ 8. Is ECM anything you would recommend to other patients on sick leave? \\ 9. Is there anything else about ECM you want to add? \\ (We tried to explore the thoughts, the concerns, and the wishes of the participants in relation to ECM.)
}

Figure SI Interview guides used for the groups and individually.

Abbreviation: ECM, early collaboration work model.

\section{Publish your work in this journal}

The Journal of Multidisciplinary Healthcare is an international, peerreviewed open-access journal that aims to represent and publish research in healthcare areas delivered by practitioners of different disciplines. This includes studies and reviews conducted by multidisciplinary teams as well as research which evaluates the results or conduct of such teams or health care processes in general. The journal covers a very wide range of areas and welcomes submissions from practitioners at all levels, from all over the world The manuscript management system is completely online and includes a very quick and fair peer-review system. Visit http://www.dovepress.com/ testimonials.php to read real quotes from published authors. 